\title{
Treatment decisions and survival for people with small-cell lung cancer
}

\author{
H A Powell ${ }^{\star 1,2}$, L J Tata ${ }^{2}$, D R Baldwin ${ }^{3}$, V A Potter ${ }^{4}$, R A Stanley ${ }^{5}$, A Khakwani ${ }^{2}$ and R B Hubbard ${ }^{1,2}$ \\ ${ }^{1}$ Nottingham Respiratory Research Unit, Clinical Sciences Building, University of Nottingham, Nottingham City Hospital, Hucknall \\ Road, Nottingham NG5 1PB, UK; ${ }^{2} E$ pidemiology \& Public Health, Clinical Sciences Building, University of Nottingham, \\ Nottingham City Hospital, Hucknall Road, Nottingham NG5 1PB, UK; ${ }^{3}$ Respiratory Medicine, Nottingham University Hospitals \\ NHS Trust, Nottingham NG5 1PB, UK; ${ }^{4}$ Department of Oncology, Nottingham University Hospitals NHS Trust, Nottingham NG5 \\ 1PB, UK and ${ }^{5} \mathrm{Health}$ and Social Care Information Centre, 1 Trevelyan Square, Boar Lane, Leeds, West Yorkshire LS1 6AE, UK
}

Background: Chemotherapy improves survival for many patients with SCLC, and hence it is important to understand variations in practice and outcomes for this treatment strategy.

Methods: We used the National Lung Cancer Audit and Hospital Episodes Statistics to determine the proportion of patients who received chemotherapy for SCLC, and assess the effects of patient and organisational factors on the odds of receiving chemotherapy and of completing four cycles. We calculated median survival and used Cox regression to determine factors that predicted survival.

Results: Of 15091 cases of SCLC, 70\% received at least one cycle of chemotherapy. More deprived people were less likely to receive chemotherapy, but patients were more likely to receive chemotherapy, and to complete $\geqslant$ four cycles, if they were referred to the lung cancer team by their GP. Median survival for those treated with chemotherapy was 12.9 months for limited and 7.3 months for extensive stage disease.

Conclusions: The Linked NLCA and HES data provide real-life measures of survival in people treated with chemotherapy and show how this is influenced by patient and tumour characteristics. These data show the characteristics of patients who are less likely to complete a full course of treatment, an adverse predictor of survival.

The mainstay of treatment for people with small-cell lung cancer (SCLC) is chemotherapy. The results of clinical trials show that treatment with a platinum agent combined with etoposide can result in a median survival of 8-12 months for people with extensive stage disease (Fukuoka et al, 1991; Roth et al, 1992; Sundstrøm et al, 2002), and up to 27 months for those with limited stage disease, particularly when combined with radiotherapy (Turrisi et al, 1999; Sundstrøm et al, 2002; Takada et al, 2002). As trials tend to include younger patients with relatively good performance status, the median survival for the full spectrum of patients is likely to be less.

Inequalities in access to surgery for people with lung cancer have been documented (Rich et al, 2011a), and it is possible that these also exist in treatments for SCLC. It is important to determine whether chemotherapy treatment rates vary by individual patient factors and/or organisational factors and the English National Lung Cancer Audit (NLCA) is a valuable resource in this context.

Data from clinical trials suggest that $\sim 75 \%$ of patients complete the intended number of chemotherapy cycles (Singh et al, 2005), but we do not know the proportion of patients in routine clinical practice for whom this is the case. An understanding of the characteristics of this group of patients could also help clinicians identify people for whom the risks of starting chemotherapy may outweigh the benefits.

We used the English National Lung Cancer Audit (NLCA) to describe the characteristics of patients with SCLC who received chemotherapy and those who went on to complete a full course. We quantified overall survival from diagnosis and following 
chemotherapy according to the patient characteristics and the number of cycles completed.

\section{MATERIALS AND METHODS}

Data sources and study population. We identified cases of histologically confirmed SCLC diagnosed between 1 January 2006 and 31 September 2011 using the English NLCA database (Health and Social Care Information Centre, 2013); patients who had undergone surgery were excluded. We used linked data from Hospital Episodes Statistics (HES), which cover all inpatient hospital care, to provide additional information on co-morbidity and chemotherapy treatment, and from the Office for National Statistics (ONS) to provide dates of registered deaths.

Chemotherapy. We assessed first-line chemotherapy treatment by including any chemotherapy given in the first 6 months after a patient's diagnosis. Following an assessment of validity of chemotherapy records in the two databases (Powell et al, 2013), people who received chemotherapy were identified using both the NLCA and HES. The NLCA records the date of the first dose of chemotherapy but every time a chemotherapy dose is delivered in a hospital inpatient setting this is captured in HES. For patients with chemotherapy records in HES, we extracted the number of cycles received. We defined a full course of chemotherapy as $\geqslant$ four cycles based on current UK recommendations (National Institute for Health and Clinical Excellence, 2011.

Treatment data entered into the NLCA and HES up to 31 March 2012 were available to us, hence all patients had at least 6 months after their diagnosis where records of chemotherapy could be identified, although some patients died before this.

Covariates. We used our established method to calculate a Charlson co-morbidity index using diagnoses recorded in inpatient HES episodes, which started any time before the date of lung cancer diagnosis (Charlson et al, 1987; Rich et al, 2011b); this was analysed in four categories $(0,1,2-3$ and $\geqslant 4)$. All other covariates were obtained from the NLCA: socio-economic status measured by postcode-derived Townsend index (in quintiles); World Health Organisation performance status (PS); route of referral to the lung cancer specialist (classified as listed in Table 1); and stage which was almost always recorded as limited or extensive but for the few cases where the more recent Tumour Node Metastases staging system was used we converted this to limited (T1-4, N0-3, M0) or extensive $(\mathrm{M} 1 \mathrm{a} / \mathrm{b})$ as appropriate (Union for International Cancer Control, 2009). We also used NLCA variables to define cases who received chemo-radiotherapy as those who had a record of either radical radiotherapy or chemo-radiotherapy within 6 months of diagnosis.

The NLCA records the trust at which the patient is first seen and the trust of their chemotherapy treatment, which is often but not always the same. We defined chemotherapy trusts as those trusts that administered chemotherapy themselves in $\geqslant 75 \%$ of their treated cases (i.e., they did not have to refer their patients to another trust for chemotherapy). We chose $75 \%$ as the cutoff after inspecting the distribution of this variable (Supplementary Figure A) but also performed sensitivity analyses using $\geqslant 50 \%$ and $\geqslant 90 \%$ as cutoffs.

Statistical methods. All analyses were performed using Stata v12 (StataCorp, TX, USA). We calculated the proportion of people who had chemotherapy according to the patient, tumour and trust characteristics defined above and used multivariate logistic regression to estimate the odds of receiving chemotherapy according to the same characteristics. For those who received chemotherapy, we estimated the odds of receiving four or more cycles (representing a completed course of chemotherapy) and also how this was associated with time to treatment and receipt of chemo-radiotherapy. We used a binary variable for time to treatment using above or below the median number of days from diagnosis to first chemotherapy dose.

We plotted Kaplan-Meier survival curves and calculated median survival from the date of diagnosis for people with limited and extensive stage disease, according to the number of cycles of chemotherapy given in the 6 months after diagnosis. If date of diagnosis was missing this was closely approximated using other dates as we have described previously (Khakwani et al, 2013). To remove the effect of immortal time bias, we also assessed survival from date of finishing chemotherapy treatment. Patients were followed up to death, or they were censored on 31 March 2013, the date of ONS death tracing for this study.

We used Cox regression to estimate survival from the date of diagnosis according to whether or not chemotherapy or chemoradiotherapy were given, route of referral and whether or not the patient was first seen in a chemotherapy trust. Hazard ratios were calculated for each of these adjusting for age, sex, performance status, co-morbidity and stage. We also estimated survival following the end of the last chemotherapy cycle according to the number of cycles given $(1-3$ or $\geqslant 4)$, time from diagnosis to treatment and trust first seen. We sought interactions between stage and all other variables in the effect on survival and checked the proportional hazards assumption in our data by inspecting Nelson-Aalen plots.

\section{RESULTS}

We identified 15724 people with histologically confirmed SCLC diagnosed between 1 January 2006 and 30 September 2011. We excluded 289 people who had surgery and 119 with a recorded treatment date before their diagnosis or after death. Trusts in one specific geographical area had an extremely high proportion of patients $(65 \%)$ with no record of chemotherapy. We believe this to have been a systematic error in data entry and excluded the 225 patients first seen in this group of trusts, leaving 15091 people (96\% of the original SCLC population) for analysis.

The mean age at diagnosis was 68 years (s.d. 9.7 years); 55\% had extensive stage disease at presentation (although stage was not recorded in $20 \%$ of cases) and more were in the most deprived Townsend quintile than any other (25\% in quintile 5) (Table 1$)$. Seventy-three percent of patients $(n=11032)$ were first seen at one of the 94 chemotherapy trusts; the 53 non-chemotherapy trusts first saw $27 \%$ of this population.

Chemotherapy. Seventy percent of patients had a record of chemotherapy; $790(7 \%)$ of these also had a record that was consistent with concurrent or sequential chemo-radiotherapy (Table 1). Within the 10582 cases treated with chemotherapy, the median time from diagnosis to initiation of treatment was 18 days (IQR 12-27) and this did not change between 2006 (19 days (13-29)) and 2011 (18 days (11-26)). For patients who first presented to a chemotherapy trust, the median time to chemotherapy was 18 days (12-27), whereas for those who presented to nonchemotherapy trusts this was 19 days (12-26).

After adjusting for other factors, patients were more likely to have chemotherapy if they were younger, had good performance status, limited stage disease and a low co-morbidity index (Table 1). People living in more socio-economically deprived areas were less likely to be treated (likelihood ratio test for trend across Townsend quintiles in adjusted analysis $P=0.0002$ ) and compared with those referred by a general practitioner (GP) those referred to secondary care by any other route were less likely to get chemotherapy, even after adjusting for other patient features. (Table 1). 
Table 1. Features of patients who had chemotherapy and odds ratios for receiving chemotherapy

\begin{tabular}{|c|c|c|c|c|c|c|c|c|}
\hline & $\begin{array}{c}\text { Total } \\
\mathbf{N}=15091\end{array}$ & $\%$ & $\begin{array}{c}\text { Had } \\
\text { chemotherapy } \\
n=10582 \\
(70 \%)\end{array}$ & $\%$ & OR & $95 \% \mathrm{Cl}$ & $\begin{array}{l}\text { Adjusted } \\
\text { OR }^{\mathrm{a}}\end{array}$ & $95 \% \mathrm{Cl}$ \\
\hline \multicolumn{9}{|l|}{ Sex } \\
\hline Female & 7126 & 47.2 & 5021 & 70.5 & 1.00 & & 1.00 & \\
\hline Male & 7965 & 52.8 & 5561 & 69.8 & 0.97 & $0.90-1.04$ & 0.98 & $0.91-1.07$ \\
\hline \multicolumn{9}{|l|}{ Age group } \\
\hline$<55$ & 1204 & 8.0 & 1,043 & 86.6 & 2.76 & $2.30-3.32$ & 2.29 & $1.87-2.80$ \\
\hline $55-59$ & 1567 & 10.4 & 1,314 & 83.9 & 2.22 & $1.89-2.59$ & 1.88 & $1.58-2.23$ \\
\hline $60-64$ & 2378 & 15.8 & 1,923 & 80.9 & 1.80 & $1.58-2.05$ & 1.73 & $1.49-1.99$ \\
\hline $65-69$ & 2766 & 18.3 & 2133 & 77.1 & 1.44 & $1.28-1.62$ & 1.38 & $1.20-1.57$ \\
\hline $70-74$ & 2856 & 18.9 & 2002 & 70.1 & 1.00 & & 1.00 & \\
\hline $75-79$ & 2384 & 15.8 & 1435 & 60.2 & 0.65 & $0.58-0.72$ & 0.63 & $0.56-0.72$ \\
\hline $80-84$ & 1380 & 9.1 & 610 & 44.2 & 0.34 & $0.30-0.39$ & 0.34 & $0.29-0.40$ \\
\hline$\geqslant 85$ & 556 & 3.7 & 122 & 21.9 & 0.12 & $0.10-0.15$ & 0.12 & $0.09-0.15$ \\
\hline \multicolumn{9}{|l|}{ Townsend quintile } \\
\hline 1 (Least deprived) (socio-economic status) & 2111 & 14.0 & 1499 & 71.0 & 1.00 & & 1.00 & \\
\hline 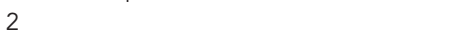 & 2704 & 17.9 & 1926 & 71.2 & 1.01 & $0.89-1.15$ & 0.96 & $0.83-1.11$ \\
\hline 3 & 2958 & 19.6 & 2083 & 70.4 & 0.97 & $0.86-1.10$ & 0.94 & $0.81-1.09$ \\
\hline 4 & 3307 & 21.9 & 2310 & 69.9 & 0.95 & $0.84-1.07$ & 0.82 & $0.71-0.94$ \\
\hline 5 (Most deprived) & 3738 & 24.8 & 2631 & 70.4 & 0.97 & $0.86-1.09$ & 0.83 & $0.72-0.96$ \\
\hline Missing & 273 & 1.8 & 133 & 48.7 & 0.39 & $0.30-0.50$ & 0.43 & $0.32-0.58$ \\
\hline \multicolumn{9}{|l|}{ Performance status } \\
\hline 0 & 2121 & 14.1 & 1909 & 90.0 & 1.00 & & 1.00 & \\
\hline 1 & 4494 & 29.8 & 3844 & 85.5 & 0.66 & $0.56-0.77$ & 0.86 & $0.72-1.02$ \\
\hline 2 & 3072 & 20.4 & 2094 & 68.2 & 0.24 & $0.20-0.28$ & 0.40 & $0.33-0.47$ \\
\hline 3 & 2017 & 13.4 & 822 & 40.8 & 0.08 & $0.06-0.09$ & 0.14 & $0.12-0.17$ \\
\hline 4 & 567 & 3.8 & 68 & 12.0 & 0.02 & $0.01-0.02$ & 0.03 & $0.02-0.04$ \\
\hline Missing & 2820 & 18.7 & 1845 & 65.4 & 0.21 & $0.18-0.25$ & 0.31 & $0.26-0.37$ \\
\hline \multicolumn{9}{|l|}{ Charlson co-morbidity index } \\
\hline 0 & 4899 & 32.5 & 3986 & 81.4 & 1.00 & & 1.00 & \\
\hline 1 & 2644 & 17.5 & 1996 & 75.5 & 0.71 & $0.63-0.79$ & 0.89 & $0.78-1.02$ \\
\hline $2-3$ & 1987 & 13.2 & 1351 & 68.0 & 0.49 & $0.43-0.55$ & 0.73 & $0.63-0.83$ \\
\hline$>3$ & 5561 & 36.8 & 3249 & 58.4 & 0.32 & $0.29-0.35$ & 0.53 & $0.48-0.59$ \\
\hline \multicolumn{9}{|l|}{ Stage } \\
\hline Extensive & 8293 & 55.0 & 5474 & 66.0 & 1.00 & & 1.00 & \\
\hline Limited & 3845 & 25.5 & 3130 & 81.4 & 2.25 & $2.05-2.47$ & 1.63 & $1.46-1.83$ \\
\hline Missing & 2953 & 19.6 & 1978 & 67.0 & 1.04 & $0.96-1.14$ & 1.01 & $0.91-1.13$ \\
\hline \multicolumn{9}{|l|}{ Route of referral } \\
\hline Emergency admission & 2323 & 15.4 & 1355 & 58.3 & 0.41 & $0.37-0.45$ & 0.68 & $0.60-0.77$ \\
\hline General practitioner & 7267 & 48.2 & 5624 & 77.4 & 1.00 & & 1.00 & \\
\hline Consultant referral & 2729 & 18.1 & 1869 & 68.5 & 0.63 & $0.58-0.70$ & 0.91 & $0.81-1.02$ \\
\hline Other (inc private) & 887 & 5.9 & 589 & 66.4 & 0.58 & $0.50-0.67$ & 0.73 & $0.61-0.87$ \\
\hline Emeergency department & 1120 & 7.4 & 630 & 56.3 & 0.38 & $0.33-0.43$ & 0.60 & $0.51-0.70$ \\
\hline Missing & 765 & 5.1 & 515 & 67.3 & 0.60 & $0.51-0.71$ & 0.79 & $0.66-0.96$ \\
\hline \multicolumn{9}{|l|}{ Trust first seen } \\
\hline Non-chemotherapy trust & 4031 & 26.7 & 2673 & 66.3 & 1.00 & & 1.00 & \\
\hline Chemotherapy trust & 11032 & 73.1 & 7893 & 71.5 & 1.25 & $1.16-1.35$ & 1.39 & $1.27-1.52$ \\
\hline Missing or trust which saw $<20$ cases & 28 & 0.2 & 16 & 57.1 & 0.88 & $0.45-1.75$ & 0.69 & $0.31-1.52$ \\
\hline
\end{tabular}


For patients first seen at a chemotherapy trust, the odds of being treated with chemotherapy were increased by $39 \%$ compared with patients seen at non-chemotherapy trusts (adjusted OR 1.39 (1.27-1.52) (Table 1). This difference persisted when we used $\geqslant 90 \%$ (adjusted OR $1.18(1.08-1.28)$ ) and $\geqslant 50 \%$ (adjusted OR $1.43(1.30-1.58))$ as the cutoff values for defining a chemotherapy trust.

Chemotherapy cycles. The proportions of people who received 0 , $1-2,3,4-5$ and $\geqslant 6$ cycles of chemotherapy are shown in Table 2. In $12 \%$ of cases, chemotherapy was only recorded in the NLCA records and hence we were not able to assess the number of cycles given. These patients are identified in the tables as 'NLCA only'. Of those with HES chemotherapy data, 63\% received a $\geqslant 4$-cycle course of chemotherapy.

Increasing age, PS, stage and co-morbidity score, and the GP route of referral were independently associated with increased odds of completing chemotherapy compared with any other referral method, as was a diagnosis to treatment interval of $<18$ days compared with those who waited longer. People who had chemoradiotherapy were more likely to complete $\geqslant 4$ cycles of chemotherapy even after adjusting for patient characteristics as shown in Table 3.

Survival. Median survival from time of diagnosis for all patients $(N=15091)$ was 6.2 months (IQR 1.5-12.4); this was 11.2 months (5.4-20.3) and 4.2 months (1.1-9.3) for people with limited and

\begin{tabular}{|c|c|c|c|c|}
\hline Cycles & $\begin{array}{c}\text { No. of } \\
\text { patients } \\
(\%) \\
N=15091\end{array}$ & $\begin{array}{l}\text { Median } \\
\text { survival } \\
\text { from } \\
\text { diagnosis } \\
\text { (IQR) }\end{array}$ & $\begin{array}{c}\text { No. of } \\
\text { patients } \\
(\%) \\
N=7866^{a}\end{array}$ & $\begin{array}{c}\text { Median survival } \\
\text { from } \\
\text { completing } \\
\text { chemotherapy } \\
\text { (IQR) }\end{array}$ \\
\hline \multicolumn{5}{|l|}{ Overall } \\
\hline $\begin{array}{l}0 \\
1-2 \\
3 \\
4-5 \\
\geq 6 \\
\text { NLCA } \\
\text { only }^{\text {b }}\end{array}$ & $\begin{array}{c}4509(29.9) \\
2320(15.4) \\
908(6.0) \\
3072(20.4) \\
2468(16.4) \\
1814(12.0)\end{array}$ & $\begin{array}{c}30(14-74) \\
85(43-185) \\
209(125-377) \\
316(213-527) \\
377(270-612) \\
230(78-396)\end{array}$ & $\begin{array}{r}1595(20.2) \\
818(10.4) \\
3000(38.1) \\
2453(31.2)\end{array}$ & $\begin{array}{c}70(24-191) \\
126(50-300) \\
189(95-405) \\
224(114-453)\end{array}$ \\
\hline \multicolumn{5}{|c|}{ Extensive stage $(\boldsymbol{N}=8293) 3972$} \\
\hline $\begin{array}{l}0 \\
1-2 \\
3 \\
4-5 \\
6 \\
\text { NLCA } \\
\text { only }^{\text {b }}\end{array}$ & $\begin{array}{c}2891(34.0) \\
1399(16.9) \\
439(5.3) \\
1432(17.3) \\
1280(15.4) \\
924(11.1)\end{array}$ & $\begin{array}{c}26(12-56) \\
73(40-149) \\
163(108-276) \\
260(187-384) \\
324(247-485) \\
177(52-315)\end{array}$ & \begin{tabular}{|c}
$925(23.8)$ \\
$386(9.7)$ \\
$1391(35.0)$ \\
$1270(32.0)$
\end{tabular} & $\begin{array}{r}53(20-126) \\
82(31-192) \\
135(68-256) \\
168(88-333)\end{array}$ \\
\hline \multicolumn{5}{|c|}{ Limited stage $(\boldsymbol{N}=3845) 2066$} \\
\hline \begin{tabular}{|l}
0 \\
$1-2$ \\
3 \\
$4-5$ \\
6 \\
NLCA \\
only $^{b}$ \\
\end{tabular} & $\begin{array}{c}715(18.6) \\
465(12.0) \\
295(7.7) \\
1112(28.9) \\
777(20.2) \\
484(12.6)\end{array}$ & $\begin{array}{c}79(25-218) \\
141(58-366) \\
301(177-552) \\
420(280-758) \\
505(342-843) \\
356(199-586)\end{array}$ & $\begin{array}{r}346(16.7) \\
276(13.3) \\
1098(53.1) \\
774(37.5)\end{array}$ & $\begin{array}{l}134(50-383) \\
213(97-461) \\
300(154-648) \\
347(183-690)\end{array}$ \\
\hline $\begin{array}{l}\mathbf{a}_{\text {Exclud }} \\
\text { died wit } \\
\mathbf{b}_{\text {NLCA }}\end{array}$ & rd of che & py but insuf & $\begin{array}{l}\text { rapy, } 181 \\
\text { lata to ca }\end{array}$ & $\begin{array}{l}\text { A only, and } 902 \text { who } \\
\text { e number of cycles. }\end{array}$ \\
\hline
\end{tabular}

extensive stage disease, respectively. Median survival by stage according to the number of chemotherapy cycles received is shown in Table 2.

Figure 1 shows survival from the date of diagnosis according to the number of cycles received and stage at presentation. People who received one or two cycles are grouped together, as are those who received four or five cycles because their survival curves were almost identical. Figure 2 shows the same survival analysis but from the end of the last chemotherapy cycle.

The Cox regression analysis from time of diagnosis showed that for people who completed chemotherapy the risk of death was $75 \%$ lower than for those who received no chemotherapy (adjusted HR 0.25, 95\% CI: 0.24-0.27) (Table 4).

Survival did not vary significantly by Townsend quintile or according to whether the patient was first seen at a chemotherapy trust. People diagnosed with SCLC as a result of an emergency admission were more likely to die than people referred by their GP (HR 1.69, 95\% CI 1.61-1.78); this association was attenuated but not fully explained by age, sex, PS, stage and co-morbidity index (adjusted HR 1.30, 95\% CI $1.23-1.37)$. Those who waited $\geqslant 18$ days between diagnosis and treatment had a lower risk of dying compared with those who waited $<18$ days (adjusted HR $0.84,95 \%$ CI $0.81-0.88$ ). There was no evidence that stage modified the effect of any of the variables on survival, and there was no evidence to reject our proportional hazards assumption.

The results were very similar when we excluded the effect of immortal time bias by assessing survival in those who had chemotherapy from the end of their last recorded cycle (Supplementary Table A).

\section{DISCUSSION}

We have used current English data to describe which patients with SCLC received chemotherapy treatment and give real-life estimates of survival. We found evidence that a patient's chances of receiving and/or completing chemotherapy treatment was related not only to their fitness but also socio-economic status, the trust at which they were first seen, the time taken from diagnosis to first treatment and their route of referral to a lung cancer specialist.

Strengths and limitations. The main strengths of this study are the large sample size and the validity of the database (Rich et al, 2011b). The NLCA estimates $98 \%$ case ascertainment since 2009 and completeness of individual data fields improves year on year (NHS Information Centre, 2012). Mortality data from the ONS ensured that our outcome data were both accurate and complete. We enhanced our chemotherapy records by comparing records in HES and the NLCA and found that use of a single data set underestimated the proportion of people who received chemotherapy. Inpatient HES data do not capture the majority of radiotherapy episodes, and therefore we relied solely on the NLCA for radiotherapy data and may have underestimated the number of patients treated.

The main limitations of the study are the lack of detailed trust level data, and the limited number of years available at present. We were not able to draw conclusions as to whether six cycles of treatment are better than four cycles and did not assess second line or ongoing therapy. There is currently no consensus on how patients who relapse, or do not completely respond, after first-line treatment should be managed, although there is some evidence that second-line therapy with the same agents is worthwhile (National Institute for Health and Clinical Excellence, 2011); novel agents are under investigation. The recently introduced systemic anticancer therapy data set (National Cancer Intelligence Network (hosted by Public Health England), 2011), linked with the NLCA will provide 
Table 3. Factors associated with completing $\geqslant 4$ cycles in patients who started chemotherapy

\begin{tabular}{|c|c|c|c|c|c|c|c|c|}
\hline & $\begin{array}{c}\text { Total } \\
\mathbf{N}=\mathbf{8 7 6 8 ^ { a }}\end{array}$ & $\%$ & $\begin{array}{c}\text { Received } \\
\geqslant 4 \text { cycles } \\
\begin{array}{c}N=5540 \\
(63 \%)\end{array}\end{array}$ & $\%$ & $\begin{array}{c}\text { OR for } \\
\text { completing } \\
\geqslant 4 \text { cycles }\end{array}$ & $95 \% \mathrm{Cl}$ & $\begin{array}{c}\text { Adjusted } \\
\text { OR }^{\mathrm{b}}\end{array}$ & $95 \% \mathrm{Cl}$ \\
\hline \multicolumn{9}{|l|}{ Sex } \\
\hline Female & 4166 & 47.5 & 2641 & 63.4 & 1.00 & & 1.00 & \\
\hline Male & 4602 & 52.5 & 2899 & 63.0 & 0.98 & $0.90-1.07$ & 0.99 & $0.91-1.09$ \\
\hline \multicolumn{9}{|l|}{ Age group } \\
\hline$<55$ & 895 & 10.2 & 618 & 69.1 & 1.41 & $1.19-1.68$ & 1.29 & $1.07-1.54$ \\
\hline $55-59$ & 1106 & 12.6 & 755 & 68.3 & 1.36 & $1.16-1.60$ & 1.26 & $1.07-1.49$ \\
\hline $60-64$ & 1620 & 18.5 & 1058 & 65.3 & 1.19 & $1.03-1.38$ & 1.15 & $0.99-1.34$ \\
\hline $65-69$ & 1777 & 20.3 & 1169 & 65.8 & 1.22 & $1.06-1.40$ & 1.21 & $1.05-1.40$ \\
\hline $70-74$ & 1625 & 18.5 & 995 & 61.2 & 1.00 & & 1.00 & \\
\hline $75-79$ & 1147 & 13.1 & 645 & 56.2 & 0.81 & $0.70-0.95$ & 0.83 & $0.71-0.98$ \\
\hline 80-84 & 496 & 5.7 & 244 & 49.2 & 0.61 & $0.50-0.75$ & 0.63 & $0.52-0.78$ \\
\hline$\geqslant 85$ & 102 & 1.2 & 56 & 54.9 & 0.77 & $0.52-1.15$ & 0.80 & $0.53-1.21$ \\
\hline \multicolumn{9}{|c|}{ Townsend quintile (socio-economic status) } \\
\hline 1 (Least deprived) & 1241 & 14.2 & 801 & 64.5 & 1.00 & & 1.00 & \\
\hline 2 & 1590 & 18.1 & 1032 & 64.9 & 1.02 & $0.87-1.19$ & 0.99 & $0.84-1.16$ \\
\hline 3 & 1743 & 19.9 & 1102 & 63.2 & 0.94 & $0.81-1.10$ & 0.93 & $0.80-1.09$ \\
\hline 4 & 1932 & 22.0 & 1213 & 62.8 & 0.93 & $0.80-1.08$ & 0.90 & $0.77-1.05$ \\
\hline 5 (Most deprived) & 2152 & 24.5 & 1348 & 62.6 & 0.92 & $0.80-1.07$ & 0.89 & $0.76-1.04$ \\
\hline Missing & 110 & 1.3 & 44 & 40.0 & 0.37 & $0.25-0.55$ & 0.37 & $0.25-0.56$ \\
\hline \multicolumn{9}{|l|}{ Performance status } \\
\hline 0 & 1626 & 18.5 & 1243 & 76.4 & 1.00 & & 1.00 & \\
\hline 1 & 3208 & 36.6 & 2168 & 67.6 & 0.64 & $0.56-0.74$ & 0.71 & $0.62-0.82$ \\
\hline 2 & 1664 & 19.0 & 903 & 54.3 & 0.37 & $0.31-0.42$ & 0.45 & $0.38-0.52$ \\
\hline 3 & 683 & 7.8 & 279 & 40.8 & 0.21 & $0.18-0.26$ & 0.27 & $0.22-0.33$ \\
\hline 4 & 53 & 0.6 & 20 & 37.7 & 0.19 & $0.11-0.33$ & 0.23 & $0.13-0.41$ \\
\hline Missing & 1534 & 17.5 & 927 & 60.4 & 0.47 & $0.40-0.55$ & 0.56 & $0.48-0.66$ \\
\hline \multicolumn{9}{|l|}{ Charlson co-morbidity index } \\
\hline 0 & 3318 & 37.8 & 2298 & 69.3 & 1.00 & & 1.00 & \\
\hline 1 & 1641 & 18.7 & 1076 & 65.6 & 0.85 & $0.75-0.96$ & 0.93 & $0.81-1.05$ \\
\hline $2-3$ & 1092 & 12.5 & 669 & 61.3 & 0.70 & $0.61-0.81$ & 0.81 & $0.70-0.94$ \\
\hline$>3$ & 2717 & 31.0 & 1497 & 55.1 & 0.54 & $0.49-0.61$ & 0.69 & $0.62-0.77$ \\
\hline \multicolumn{9}{|l|}{ Stage } \\
\hline Extensive & 4550 & 51.9 & 2712 & 59.6 & 1.00 & & 1.00 & \\
\hline Limited & 2646 & 30.2 & 1889 & 71.4 & 1.69 & $1.53-1.87$ & 1.44 & $1.29-1.61$ \\
\hline Missing & 1572 & 17.9 & 939 & 59.7 & 1.01 & $0.89-1.13$ & 0.95 & $0.84-1.08$ \\
\hline \multicolumn{9}{|l|}{ Time to treatment } \\
\hline$<18$ days & 4305 & 49.1 & 2773 & 64.4 & 1.00 & & 1.00 & \\
\hline$\geqslant 18$ days & 4463 & 50.9 & 2767 & 62.0 & 0.90 & $0.83-0.98$ & 0.81 & $0.74-0.89$ \\
\hline \multicolumn{9}{|l|}{ Route of referral } \\
\hline Emergency admission & 1157 & 13.2 & 626 & 54.1 & 0.56 & $0.49-0.64$ & 0.68 & $0.59-0.78$ \\
\hline General Practitioner & 4666 & 53.2 & 3166 & 67.9 & 1.00 & & 1.00 & \\
\hline Consultant referral & 1556 & 17.7 & 950 & 61.1 & 0.74 & $0.66-0.84$ & 0.85 & $0.75-0.97$ \\
\hline Other (inc private) & 464 & 5.3 & 282 & 60.8 & 0.73 & $0.60-0.89$ & 0.80 & $0.66-0.98$ \\
\hline Emergency Department & 514 & 5.9 & 269 & 52.3 & 0.52 & $0.43-0.63$ & 0.63 & $0.52-0.77$ \\
\hline Missing & 411 & 4.7 & 247 & 60.1 & 0.71 & $0.58-0.88$ & 0.82 & $0.66-1.01$ \\
\hline \multicolumn{9}{|l|}{ Trust first seen } \\
\hline Non-chemotherapy trust & 2064 & 23.5 & 1260 & 61.0 & 1.00 & & 1.00 & \\
\hline Chemotherapy trust & 6688 & 76.3 & 4271 & 63.9 & 1.13 & $1.02-1.25$ & 1.14 & $1.03-1.27$ \\
\hline Missing/trust which saw $<20$ cases & 16 & 0.2 & 9 & 56.3 & 0.82 & $0.30-2.21$ & 0.63 & $0.23-1.72$ \\
\hline \multicolumn{9}{|l|}{ Radiotherapy } \\
\hline No chemo-radiotherapy & 7978 & 91.0 & 4919 & 61.7 & 1.00 & & 1.00 & \\
\hline Chemo-radiotherapy & 790 & 9.0 & 621 & 78.6 & 2.29 & $1.92-2.72$ & 1.74 & $1.44-2.09$ \\
\hline 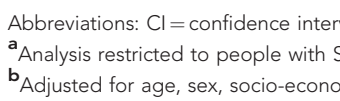 & odds ratio & & T & 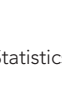 & & & & \\
\hline
\end{tabular}



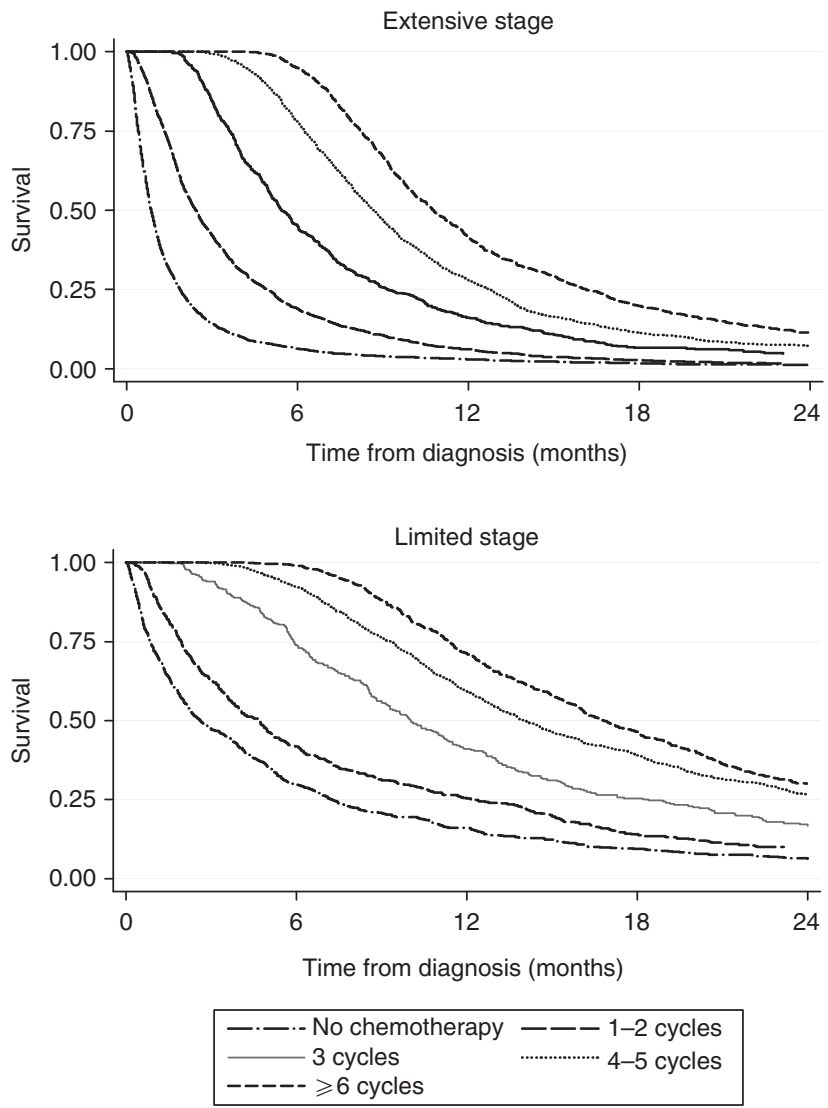

Figure 1. Kaplan-Meier plots showing survival after diagnosis by number of cycles recorded, for limited and extensive stage small-cell lung cancer.

more detailed real-life data, which will help us to address these important questions.

Comparison with trial data. Although we recognise that our assessment of chemotherapy within observational populationbased data cannot be used to directly assess effectiveness, comparisons with trial data are valuable.

Number of cycles. There are few studies examining the number of cycles of chemotherapy actually given for SCLC outside of clinical trials. Burgers et al (2002) found no significant difference in the proportion of patients who received four or more cycles of chemotherapy within a trial (49/60) compared with outside of a trial $(35 / 46)$ in their UK hospital. However, they only included patients who were eligible for one of these two SCLC chemotherapy trials.

We chose four cycles to represent a complete course of chemotherapy, but acknowledge that practice differs in this respect. We found median survival to be longer after completion of six or more cycles of chemotherapy compared with four to five cycles, but cannot conclude that six cycles are preferable to four as we do not have data on the fitness of the patients at the point of finishing four cycles or reasons for discontinuing treatment.

Survival. Median survival for 105 people with limited stage SCLC treated with etoposide and carboplatin in a randomised trial by the Norwegian Lung Cancer Study Group was 14.5 months from diagnosis and 8.4 months for 113 people with extensive stage (Sundstrøm et al, 2002). This is similar for patients in our study (12.9 and 7.3 months).

In our study, $71 \%$ of patients with limited stage who started chemotherapy and $60 \%$ of those with extensive stage received four
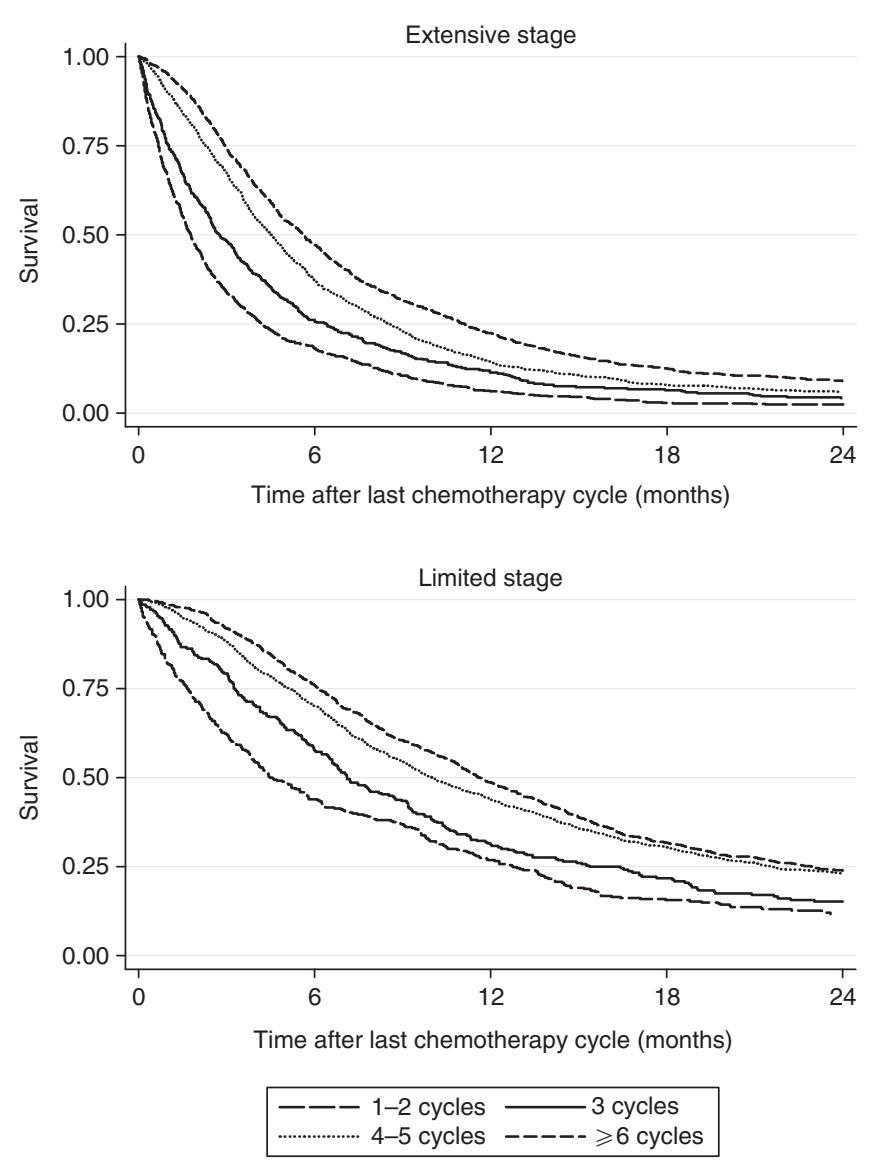

Figure 2. Kaplan-Meier plots showing survival after final chemotherapy cycle by number of cycles recorded, for limited and extensive stage small-cell lung cancer.

or more cycles. This is lower than in the Norwegian trial where $70 \%$ of patients overall received five cycles; patients treated with chemotherapy in that trial were fitter and younger than those in the NLCA (median age 64 vs 67 years).

\section{Clinical relevance}

Route of referral. Those who were diagnosed as a result of an emergency hospital attendance were less likely to start chemotherapy, less likely to complete a course and less likely to survive than those referred by a GP, even after adjusting for patient fitness and stage. There is likely to be an element of residual confounding by patient fitness in these estimates, but other studies have also found this group to have poor survival (Elliss-Brookes et al, 2012; McPhail et al, 2013). Given that almost a fifth of our patients presented by an emergency route (which is similar to or lower than other estimates for lung cancer overall in the United Kingdom (Elliss-Brookes et al, 2012)), this is an extremely important group for UK clinicians to target if overall survival from lung cancer is to improve.

Time to initiation of treatment. The average time from diagnosis to first chemotherapy dose was 18 days with $25 \%$ of patients waiting more than 27 days. A period of longer than 18 days was associated with improved survival, and this is likely to reflect the impact of prioritising patients who are unwell with aggressive disease and poor performance status.

Those potentially fitter patients who waited longer than 18 days were less likely to complete four cycles of chemotherapy than those who were treated more quickly. Completing $\geqslant 4$ cycles was a 
Table 4. Hazard ratios for death (analysis from time of diagnosis)

\begin{tabular}{|c|c|c|c|c|c|c|c|}
\hline $\begin{array}{l}\text { Survival from } \\
\text { diagnosis }\end{array}$ & $\begin{array}{c}\text { Total } \\
\text { patients } \\
\mathbf{N}=15091\end{array}$ & $\begin{array}{c}\text { Deaths } \\
n=10041\end{array}$ & $\%$ & HR & $95 \% \mathrm{Cl}$ & $\begin{array}{c}\text { Adjusted } \\
\mathrm{HR}^{\mathrm{a}}\end{array}$ & $95 \% \mathrm{Cl}$ \\
\hline \multicolumn{8}{|c|}{ Townsend quintile } \\
\hline 1 (Least deprived) & 2111 & 1981 & 93.8 & 1.00 & & 1.00 & \\
\hline 2 & 2704 & 2558 & 94.6 & 1.02 & $0.96-1.08$ & 1.03 & $0.98-1.10$ \\
\hline 3 & 2958 & 2788 & 94.3 & 1.02 & $0.96-1.08$ & 1.01 & $0.95-1.07$ \\
\hline 4 & 3307 & 3109 & 94.0 & 1.01 & $0.95-1.06$ & 1.03 & $0.98-1.09$ \\
\hline 5 (Most deprived) & 3738 & 3517 & 94.1 & 0.99 & $0.94-1.05$ & 1.02 & $0.96-1.08$ \\
\hline Missing & 273 & 262 & 96.0 & 1.69 & $1.49-1.93$ & 1.39 & $1.22-1.58$ \\
\hline
\end{tabular}

\begin{tabular}{|c|c|c|c|c|c|c|c|}
\hline \multicolumn{8}{|l|}{ Route of referral } \\
\hline Emergency admission & 2323 & 2246 & 96.7 & 1.69 & $1.61-1.78$ & 1.30 & $1.24-1.37$ \\
\hline General Practitioner & 7267 & 6738 & 92.7 & 1.00 & & 1.00 & \\
\hline Consultant referral & 2729 & 2566 & 94.0 & 1.19 & $1.14-1.25$ & 1.01 & $0.96-1.06$ \\
\hline Other (inc private) & 887 & 836 & 94.3 & 1.18 & $1.10-1.27$ & 1.03 & $0.96-1.11$ \\
\hline Emergency Department & 1120 & 1086 & 97.0 & 1.66 & $1.56-1.77$ & 1.29 & $1.21-1.37$ \\
\hline Missing & 765 & 743 & 97.1 & 1.26 & $1.17-1.36$ & 1.12 & $1.04-1.21$ \\
\hline
\end{tabular}

\section{Radiotherapy}

\begin{tabular}{|l|c|c|c|c|c|c|c|}
\hline No chemotherapy & 4509 & 4448 & 98.6 & 1.00 & 1.00 & 0.28 & $0.27-0.29$ \\
Chemotherapy only & 9590 & 8962 & 93.5 & 0.35 & $0.34-0.37$ \\
Chemo-radiotherapy & 992 & 805 & 81.1 & 0.16 & $0.15-0.18$ & 0.26 \\
\hline
\end{tabular}

\begin{tabular}{|c|c|c|c|c|c|c|c|}
\hline \multicolumn{8}{|c|}{ Chemotherapy cycles } \\
\hline No chemotherapy & 4509 & 4448 & 98.6 & 1.00 & & 1.00 & \\
\hline $1-3$ cycles & 3228 & 3115 & 96.5 & 0.45 & $0.43-0.47$ & 0.54 & $0.52-0.57$ \\
\hline$\geqslant 4$ cycles & 5540 & 4936 & 89.1 & 0.20 & $0.19-0.21$ & 0.25 & $0.24-0.27$ \\
\hline NLCA record only & 1814 & 1716 & 94.6 & 0.31 & $0.29-0.33$ & 0.39 & $0.37-0.41$ \\
\hline
\end{tabular}

Time to treatment

\begin{tabular}{|c|c|c|c|c|c|c|c|}
\hline $\begin{array}{l}<18 \text { days } \\
\geqslant 18 \text { days } \\
\text { No chemotherapy }\end{array}$ & $\begin{array}{l}5137 \\
5445 \\
4509\end{array}$ & $\begin{array}{l}4834 \\
4933 \\
4448\end{array}$ & $\begin{array}{l}94.1 \\
90.6 \\
98.6\end{array}$ & $\begin{array}{l}1.00 \\
0.80 \\
3.30\end{array}$ & $\begin{array}{l}0.77-0.83 \\
3.17-3.44\end{array}$ & $\begin{array}{l}1.00 \\
0.84 \\
2.64\end{array}$ & $\begin{array}{l}0.81-0.88 \\
2.52-2.76\end{array}$ \\
\hline \multicolumn{8}{|l|}{ Trust first seen } \\
\hline $\begin{array}{l}\text { Non-chemotherapy trust } \\
\text { Chemotherapy trust } \\
\text { Missing/trust that saw } \\
<20 \text { cases }\end{array}$ & $\begin{array}{c}4276 \\
10779 \\
36\end{array}$ & $\begin{array}{c}4011 \\
10171 \\
33\end{array}$ & $\begin{array}{l}93.8 \\
94.4 \\
91.7\end{array}$ & $\begin{array}{l}1.00 \\
1.01 \\
0.99\end{array}$ & $\begin{array}{l}0.97-1.04 \\
0.70-1.39\end{array}$ & $\begin{array}{l}1.00 \\
0.99 \\
0.93\end{array}$ & $\begin{array}{l}0.95-1.02 \\
0.66-1.32\end{array}$ \\
\hline
\end{tabular}

Abbreviations: $\mathrm{Cl}=$ confidence interval; $\mathrm{HR}=$ hazard ratio; $\mathrm{NLCA}=$ National Lung Cancer Audit.

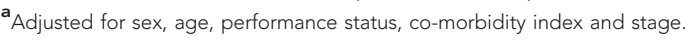

strong predictor of better survival; however, the direction of causation is very uncertain and it may well be that non-completion of chemotherapy is due to death, rather than the other way around. Despite this uncertainly we would suggest that earlier treatment for all may improve survival. The 2011 UK guidelines on SCLC recommend that all patients are assessed by an oncologist within a week of deciding to recommend treatment (National Institute for Health and Clinical Excellence, 2011).

Trust features. People first seen at chemotherapy trusts did not survive longer than those seen at non-chemotherapy trusts despite being more likely to receive chemotherapy. Of patients first seen at a non-chemotherapy trust $66.3 \%$ had chemotherapy compared with $71.5 \%$ of those seen a chemotherapy trust. It is possible that treating an average of $5 \%$ more of their patients was not enough to translate into an overall survival benefit for chemotherapy trusts, but also that the additional patients treated were less fit and higher risk in ways that are difficult to measure.

\section{CONCLUSION}

These national data reflect the decisions that were made about chemotherapy treatment in clinical practice in England. We have provided real-life measures of survival in those treated with chemotherapy taking into account patient and tumour characteristics and have described which patients were less likely to complete a full course of treatment based on key sociodemographic and clinical features. We were unable to determine whether six cycles of treatment are better than four cycles due to the influence of immortal time bias and a lack of longitudinal data on patient fitness and reasons for stopping treatment.

There is variation in the time from diagnosis to initiation of treatment, and some evidence of inequalities in access to treatment with particularly poor outcomes for those who present via the emergency route. This further supports the need for initiatives that improve early presentation and diagnosis. Our finding that 
chemotherapy trusts treat a greater proportion of patients but that this does not show a survival benefit requires further work to clarify the reasons, but it may be that better selection of patients for treatment and continuation of treatment is a key.

\section{ACKNOWLEDGEMENTS}

The National Lung Cancer Audit is commissioned by the Healthcare Quality Improvement Partnership (HQIP). Data linkage was performed and data were provided to the authors by the Health and Social Care Information Centre. We thank the NLCA team and all clinicians, nurses and administrators who have entered data. HAP is funded by the National Institute of Health Research (NIHR) through the Nottingham Respiratory Research Unit. RBH is the British Lung Foundation/GlaxoSmithKline Professor of respiratory epidemiology.

\section{REFERENCES}

Burgers JA, Arance A, Ashcroft L, Hodgetts J, Lomax L, Thatcher N (2002) Identical chemotherapy schedules given on and off trial protocol in small cell lung cancer response and survival results. Br J Cancer 87: 562-566.

Charlson ME, Pompei P, Ales KL, Mackenzie CR (1987) A new method of classifying prognostic co-morbidity in longitudinal-studies-development and validation. J Chronic Dis 40: 373-383.

Elliss-Brookes L, McPhail S, Ives A, Greenslade M, Shelton J, Hiom S, Richards M (2012) Routes to diagnosis for cancer-determining the patient journey using multiple routine data sets. Br J Cancer 107: $1220-1226$.

Fukuoka M, Furuse K, Saijo N, Nishiwaki Y, Ikegami H, Tamura T, Shimoyama M, Suemasu K (1991) Randomized trial of cyclophosphamide, doxorubicin, and vincristine versus cisplatin and etoposide versus alternation of these regimens in small-cell lung cancer. J Natl Cancer Inst 83: 855-861.

Health and social care information centre (2013) National Lung Cancer Audit [Online]. Available at: http://www.hscic.gov.uk/lung (accessed 7th August 2013).

Khakwani A, Rich AL, Tata LJ, Powell HA, Stanley RA, Baldwin DR, Hubbard RB (2013) The pathological confirmation rate of lung cancer in England using the NLCA database. Lung Cancer 79: 125-131.

Mcphail S, Elliss-Brookes L, Shelton J, Ives A, Greenslade M, Vernon S, Morris EJA, Richards M (2013) Emergency presentation of cancer and short-term mortality. Br J Cancer 109: 2027-2034.

National cancer intelligence network (Hosted by Public Health England (2011) SACT Systemic Anti-cancer Therapy-Chemotherapy dataset [Online]. Available at: http://www.chemodataset.nhs.uk/home.
National institute for health and clinical excellence (2011) The diagnosis and treatment of lung cancer (update) NICE guideline.

NHS Information Centre (2012) National Lung Cancer Audit 2012, Report for the Audit period 2011.

Powell HA, Tata LJ, Baldwin DR, Stanley RA, Hubbard RB (2013) P15 Identifying patients who receive chemotherapy for small-cell lung cancer using large datasets. Thorax 68: A81.

Rich AL, Tata LJ, Free CM, Stanley RA, Peake MD, Baldwin DR, Hubbard RB (2011a) Inequalities in outcomes for non-small cell lung cancer: the influence of clinical characteristics and features of the local lung cancer service. Thorax 66: 1078-1084.

Rich AL, Tata LJ, Stanley RA, Free CM, Peake MD, Baldwin DR, Hubbard RB (2011b) Lung cancer in England: Information from the National Lung Cancer Audit (LUCADA). Lung cancer 72: 16-22.

Roth BJ, Johnson DH, Einhorn LH, Schacter LP, Cherng NC, Cohen HJ, Crawford J, Randolph JA, Goodlow JL, Broun GO (1992) Randomized study of cyclophosphamide, doxorubicin, and vincristine versus etoposide and cisplatin versus alternation of these two regimens in extensive smallcell lung cancer: a phase III trial of the Southeastern Cancer Study Group. J Clin Oncol 10: 282-291.

Singh S, Parulekar W, Murray N, Feld R, Evans WK, Tu D, Shepherd FA (2005) Influence of sex on toxicity and treatment outcome in small-cell lung cancer. J Clin Oncol 23: 850-856.

Sundstrøm S, Bremnes RM, Kaasa S, Aasebø U, Hatlevoll R, Dahle R, Boye N, Wang M, Vigander T, Vilsvik J, Skovlund E, Hannisdal E, Aamdal S.

Group, F. T. N. L. C. S. (2002) Cisplatin and etoposide regimen is superior to cyclophosphamide, epirubicin, and vincristine regimen in small-cell lung cancer: results from a randomized phase III trial with 5 years' follow-up. J Clin Oncol 20: 4665-4672.

Takada M, Fukuoka M, Kawahara M, Sugiura T, Yokoyama A, Yokota S, Nishiwaki Y, Watanabe K, Noda K, Tamura T, Fukuda H, Saijo N. Group, F. T. M. O. T. J. C. O. (2002) Phase III study of concurrent versus sequential thoracic radiotherapy in combination with cisplatin and etoposide for limited-stage small-cell lung cancer: results of the Japan Clinical Oncology Group Study 9104. J Clin Oncol 20: 3054-3060.

Turrisi AT, Kim K, Blum R, Sause WT, Livingston RB, Komaki R, Wagner H, Aisner S, Johnson DH (1999) Twice-Daily compared with once-daily thoracic radiotherapy in limited small-cell lung cancer treated concurrently with cisplatin and etoposide. $N$ Engl J Med 340: 265-271.

Union for international cancer control (2009) TNM Classification of Malignant Tumours, 7th edn. Wiley-Blackwell: Oxford, UK.

This work is published under the standard license to publish agreement. After 12 months the work will become freely available and the license terms will switch to a Creative Commons AttributionNonCommercial-Share Alike 3.0 Unported License.

Supplementary Information accompanies this paper on British Journal of Cancer website (http://www.nature.com/bjc) 